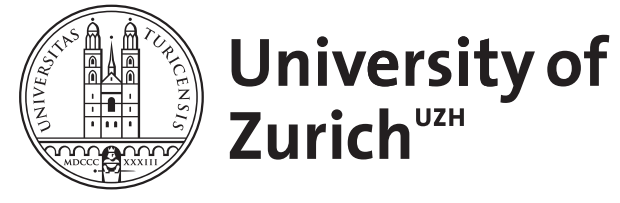

\title{
Processes underlying sleep regulation
}

Borbély, A A

\begin{abstract}
Sleep is regulated by homeostatic, circadian and ultradian processes. Slow waves and sleep spindles are EEG markers of sleep processes which have counterparts at the cellular level. The interaction of homeostatic and circadian sleep regulation has been formalized in the two-process model and validated in experiments. Sleep is not only a global brain phenomenon but also a regional cerebral process whose intensity may be influenced by prior activity during waking.
\end{abstract}

DOI: https://doi.org/10.1159/000023156

Posted at the Zurich Open Repository and Archive, University of Zurich ZORA URL: https://doi.org/10.5167/uzh-885

Journal Article

Published Version

Originally published at:

Borbély, A A (1998). Processes underlying sleep regulation. Hormone Research, 49(3-4):114-117.

DOI: https://doi.org/10.1159/000023156 


\section{Hormone Research}

\section{Alexander A. Borbély}

Institute of Pharmacology, University of Zürich, Switzerland
Horm Res 1998;49:114-117

\section{Processes Underlying Sleep Regulation}

\begin{abstract}
Sleep is regulated by homeostatic, circadian and ultradian processes. Slow waves and sleep spindles are EEG markers of sleep processes which have counterparts at the cellular level. The interaction of homeostatic and circadian sleep regulation has been formalized in the two-process model and validated in experiments. Sleep is not only a global brain phenomenon but also a regional cerebral process whose intensity may be influenced by prior activity during waking.
\end{abstract}

The regulatory processes underlying the manifestation of sleep and the release of hormones exhibit similarities. These include: (1) a sleep-waking dependent component of non-rapid-eye movement (nonREM) sleep intensity of which EEG slow-wave activity (SWA) is a reliable marker, and the release of growth hormone which occurs preferentially during deep nonREM sleep [1]; (2) a clock-like circadian process which is largely independent of sleep and waking, and which modulates both the nonREM/REM sleep ratio and hormones such as cortisol and melatonin [2], and (3) an ultradian process which is responsible for the alternation of the two basic sleep states nonREM sleep and REM sleep, which is associated with a variation of renin release [3].

\section{Two-Process Model and SWA}

The two-process model of sleep regulation posits that a homeostatic process (Process $\mathrm{S}$ ) rises during waking and declines during sleep, and interacts with a circadian process (Process $\mathrm{C}$ ) that is independent of sleep and waking
[4-6]. The time course of the homeostatic variable $\mathrm{S}$ was derived from EEG SWA. Under physiological conditions, this EEG variable constitutes an index of 'sleep intensity' which changes as a function of prior sleep and waking. Sleep deprivation enhances SWA and this enhancement depends on duration of waking $[7,8]$. 'Sleep pressure' is not only augmented by sleep deprivation but reduced by daytime naps. According to the two-process model, the sum of cumulated SWA during the nap and the post-nap sleep episode is equal to the cumulated value of the baseline sleep episode. This prediction was confirmed in recent studies $[9,10]$.

Sleep spindles, another salient feature of the nonREM sleep EEG, can be measured by 'spindle frequency activity' (SFA; spectral power density in the $12-15 \mathrm{~Hz}$ band). Unlike SWA, SFA does not decrease during nocturnal sleep and, on average, shows an increasing trend. High values are seen at the onset and termination of nonREM sleep episodes. The dynamics of SFA show both a sleepdependent and a circadian component $[11,12]$ and exhibit a complex relationship to SWA [12-16].

\begin{tabular}{ll}
\hline KARGER & ( 1998 S. Karger AG, Basel \\
Fax +4161306 1234 & 0301-0163/98/0494-0114\$15.00/0 \\
$\begin{array}{l}\text { E-Mail karger@karger.ch } \\
\text { www.karger.com }\end{array}$ & This article is also accessible online at: \\
http://BioMedNet.com/karger
\end{tabular}

Prof. Alexander A. Borbély

Institute of Pharmacology, University of Zürich

Winterthurerstrasse 190

CH-8057 Zürich (Switzerland)

Tel. +41 1635 5960, Fax +41 1635 5707, E-Mail borbely@pharma.unizh.ch 


\section{Origin of EEG Slow Waves and Spindles}

Recently, slow waves and sleep spindles were shown to be closely related to cellular changes at the level of thalamic and cortical neurons. The progressive hyperpolarization of thalamocortical neurons during sleep induces fluctuations in the membrane potential in the frequency range of the sleep EEG. Oscillations in the membrane potential of thalamocortical neurons occur in the range of sleep spindles when an intermediate level of hyperpolarization prevails, whereas fluctuations in the delta range are seen when the level of hyperpolarization is high [17-19]. Synchronized network oscillations were demonstrated to cease spontaneously at least in part through the persistent activation of a hyperpolarization-activated cation conductance [20]. The oscillations at the neuronal level are associated with corresponding changes in the EEG. Thus the progressive hyperpolarization of thalamocortical neurons after sleep onset [21] may account for the presence of SFA in the initial part of a nonREM sleep episode and for the predominance of slow waves in the middle portion [13,14]. This progression of changes is enhanced when sleep pressure is high $[14,22]$ and is retarded when sleep pressure is reduced [10]. Recently, a slow component $(<1 \mathrm{~Hz})$ observed at the cellular level [23-25] was also identified in the sleep EEG [26]. Taken together these new developments indicate that sleep homeostasis can be investigated concomitantly at the microscopic level of neuronal membranes and at the macroscopic level of the EEG.

\section{Independence and Interaction of Process S and C}

Several lines of evidence point to the independent regulation of the homeostatic and circadian facet of sleep. Thus, rats rendered arrhythmic by lesions of the suprachiasmatic nuclei maintained their ability to respond to sleep loss by a rise in SWA and REM sleep [27-29]. Recent experiments in the same species demonstrated that animals exposed to different photoperiods showed dramatic changes in the 24-hour distribution of sleep and waking while nonREM sleep homeostasis remained unaffected [30]. Similar results were obtained in the chipmunk [31] and the Djungarian hamster [32]. Finally, strong support for the basic assumptions of the two-process model has been obtained from human forced desynchrony experiments in which the homeostatic and circadian facet of sleep could be separately analyzed. In this protocol, subjects were scheduled to a 28-hour sleep-waking cycle [11, 33]. During one third of the cycle the lights were off and the subjects were encouraged to sleep. Since under these experimental conditions the free-running circadian rhythm has a period of 24.1-24.2 h [34], the sleep episodes occurred at different circadian phases. The data showed that sleep propensity was at the maximum when the circadian rhythm of rectal temperature was at the minimum. Sleep propensity gradually decreased on the rising limb of the rectal temperature rhythm and reached the minimum $16 \mathrm{~h}$ after the temperature minimum. This phase corresponds to the habitual bedtime under entrained conditions. When sleep was initiated at this phase, sleep continuity was high. In contrast, poor sleep continuity was observed when sleep was initiated after the temperature minimum.

In accordance with the basic assumption, SWA, the marker of Process $S$, was shown to be determined mainly by homeostatic (i.e. sleep-waking dependent) factors, whereas REM sleep (or rather the REM sleep/nonREM sleep ratio) depended on both homeostatic and circadian factors. Furthermore, a previously postulated sleep-related inhibition of REM sleep [4] was confirmed by the results of the forced desynchrony study. The data from these experiments also showed that not only the timing of sleep but also the changes in daytime vigilance are governed by the interaction of Process S and C. The rising homeostatic sleep pressure during waking is compensated by the declining circadian sleep propensity [5, 35-37]. Conversely, during sleep the rising circadian sleep propensity may serve to counteract the declining homeostatic sleep pressure, thereby ensuring the maintenance of sleep.

\section{Sleep - A Local Use-Dependent Process?}

Although it has been clearly demonstrated that the level of SWA is determined by the duration of prior wakefulness, the physiological significance of this relationship and the underlying mechanisms are still obscure. Recently, the question arose whether sleep represents a global or a local brain process. The observations that the dolphin does not exhibit deep slow wave sleep in both hemispheres simultaneously, and that the selective deprivation of unihemispheric sleep gives rise to a unihemispheric slow wave sleep rebound [38], shows that the sleep process is not necessarily present in the entire brain. Two hypotheses were advanced which both imply that regional increases of neuronal activity and metabolic demand during wakefulness may result in selective changes in EEG synchronization of these neuronal populations during nonREM sleep [39, 40]. Benington and Heller [40] proposed 

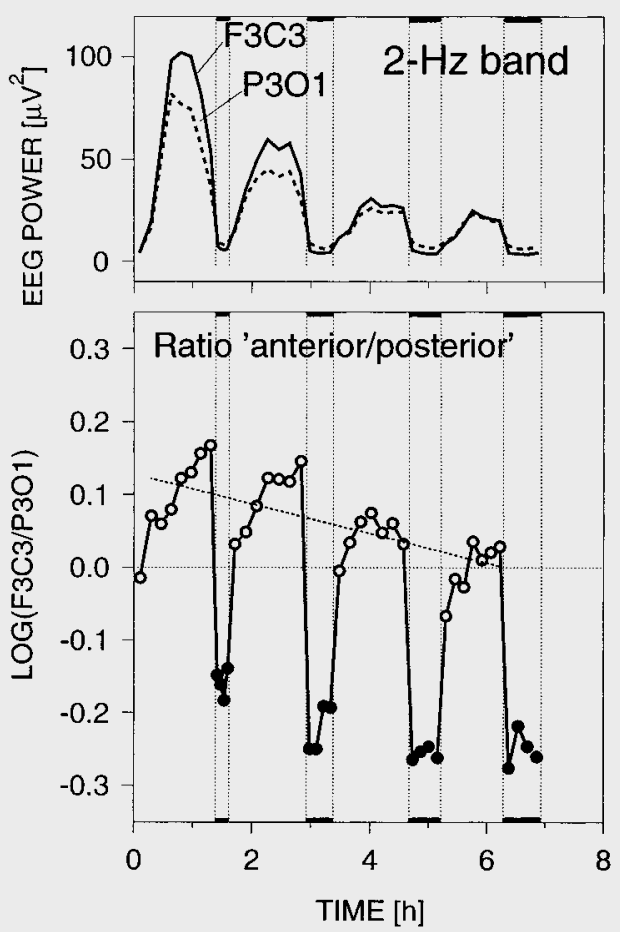

Fig. 1. Time course of EEG power during sleep in the 2-Hz bin (upper panel) for the anterior (F3-C3) and posterior (P3-O1) derivation, and of the corresponding log-transformed ratio (lower panels). Mean values ( $\mathrm{n}=20$ subjects; 34 nights). Individual nonREM sleep episodes were subdivided into 7 equal intervals, REM sleep episodes into 4 intervals, and the time between lights-off and sleep onset was represented as 1 interval. Data were aligned with respect to sleep onset (cycle 1) or with respect to the first occurrence of stage 2 after a REM sleep episode (cycles 2-4). REM sleep is indicated by horizontal black bars at the top and bottom. Linear regression lines across nonREM sleep episodes are plotted for $2-$ and $6-\mathrm{Hz}$ ratio plots $(7$ values per episode; $\mathrm{p}<0.05$ ) [modified from 47].

that adenosine, which is released upon increased metabolic demand via facilitated transport by neurons and glia cells throughout the CNS, promotes slow EEG potentials. Thus a use-dependent, local mechanism would underlie the sleep-deprivation-induced changes in the sleep EEG. Recent results support this notion. They include the sleepinducing effect of adenosine agonists administered by intracerebroventricular [41] or subarachnoidal infusion [42] as well as the attenuation of the waking-induced increase of SWA by the adenosine antagonist caffeine in the rat [43] and human [44, 45].
The tenet of a local, use-dependent increase of sleep intensity was tested by investigating whether a local activation of a particular brain region during wakefulness affects the EEG recorded from the same site during sleep [46]. An intermittent vibratory stimulus was applied to the left or right hand during the 6-hour period prior to sleep to activate the contralateral somatosensory cortex. Stimulation of the right (dominant) hand resulted in a shift of power in the nonREM sleep EEG towards the left hemisphere. This effect was most prominent in the delta range, was limited to the first hour of sleep and was restricted to the central derivation situated over the somatosensory cortex. Finally, a recent topographical study revealed a sleep-dependent hyperfrontality of SWA which varies in the course of sleep $[47,48]$. Thus in the initial two nonREM sleep episodes, the power in the 2-Hz band was dominant at the frontal derivation, whereas in the second part of sleep the anteroposterior gradient vanished (fig. 1). This finding is consistent with the notion that the sleep process may occur in a topographically graded manner by involving preferentially those neuronal populations that have been most activated during waking. It could be speculated that the progressive anteroposterior shift in power in the low-frequency range reflects a high 'need of recovery' in frontal parts of the cortex which seem to exhibit the largest activity during wakefulness [49]. Experiments involving a specific manipulation of daytime activity are required to test this possibility. In the framework of the two-process model, the results indicate that Process $\mathrm{S}$ declines in the anterior region of the brain at a steeper rate than in posterior regions and that therefore the homeostatic nonREM sleep-regulating process may exhibit regional differences. The concept of local aspects of sleep has considerable implications for the study of cerebral mechanisms which are involved in the control of hormonal changes. 


\section{References}

1 Van Cauter E, Copinschi G: Interactions between growth hormone secretion and sleep; in Smith RG, Thorner MO (eds): Human Growth Hormone: Basic and Clinical Research. Totowa/NJ, The Humana Press, 1997.

2 Van Cauter E: Hormones and sleep; in Kales A (ed): Pharmacology of Sleep. Berlin, Springer, 1995

3 Brandenberger G, Follenius M, Goichot B, Saini J, Spiegel K, Ehrhart J, Simon C: Twentyfour-hour profiles of plasma renin activity in relation to the sleep-wake cycle. J Hypertens 1994:12:277-283.

4 Borbély AA: A two-process model of sleep regulation. Hum Neurobiol 1982;1:195-204.

5 Daan S, Beersma DGM, Borbély AA: The timing of human sleep: Recovery process gated by a circadian pacemaker. Am J Physiol 1984; 246:R161-R178.

6 Borbély AA, Achermann P: Concepts and models of sleep regulation: An overview. J Sleep Res 1992;1:63-79.

7 Borbély AA, Baumann F, Brandeis D, Strauch I, Lehmann D: Sleep deprivation: Effect on sleep stages and EEG power density in man. Electroencephalogr Clin Neurophysiol 1981; 51:483-493.

8 Dijk DJ, Brunner DP, Beersma DGM, Borbély AA: Slow wave sleep and electroencephalogram power density as a function of prior waking and circadian phase. Sleep 1990;13:430440.

9 Feinberg I, Maloney T, March JD: Precise conservation of nonREM Period 1 (nonREMP1) delta across naps and nocturnal sleep: Implications for REM latency and nonREM/REM alternation. Sleep 1992;15:400-403.

10 Werth E, Dijk DJ, Achermann P, Borbély AA: Dynamics of the sleep EEG after an early evening nap: Experimental data and simulations. Am J Physiol 1996;271:R501-R510.

11 Dijk DJ, Czeisler CA: Contribution of the circadian pacemaker and the sleep homeostat to sleep propensity, sleep structure and electroencephalographic slow waves and sleep spindle activity in humans. J Neurosci 1995;15:35263538 .

12 Aeschbach D, Dijk DJ, Borbély AA: Dynamics of EEG spindle frequency activity during extended sleep in humans: Relationship to slowwave activity and time of day. Brain Res 1997; 748:131-136.

13 Aeschbach D, Borbély AA: All-night dynamics of the human sleep EEG. J Sleep Res 1993;2: $70-81$.

14 Dijk DJ, Hayes B, Czeisler CA: Dynamics of electroencephalographic sleep spindles and slow wave activity in men: Effect of sleep deprivation. Brain Res 1993;626:190-199.

15 Aeschbach D, Dijk DJ, Trachsel L, Brunner DP, Borbély AA: Dynamics of slow-wave activity and spindle frequency activity in the human sleep EEG: Effect of midazolam and zopiclone. Neuropsychopharmacology 1994;11:237-244.

16 Uchida S, Atsumi Y, Kojima T: Dynamic relationships between sleep spindles and delta waves during a NREM period. Brain Res Bull 1994;33:351-355.

17 Steriade M, McCormick DA; Sejnowski TJ: Thalamocortical oscillations in the sleeping and aroused brain. Science 1993;262:679-685.

18 Steriade M, Contreras D, Amzica F: Synchronized sleep oscillations and their paraoxysmal developments. Trends Neurosci 1994;17:199_ 208.

19 McCormick DA, Bal T: Sleep and arousal: Thalamocortical mechanisms. Annu Rev Neurosci 1997;20:185-215.

20 Bal T, McCormick DA: What stops synchronized thalamocortical oscillations? Neuron 1996; 17:297-308.

21 Hirsch JC, Fourment A, Marc ME: Sleep-related variations of membrane potential in the lateral geniculate body relay neurons of the cat. Brain Res 1983;259:308-312.

22 Aeschbach D, Cajochen C, Landolt HP, Borbély AA: Homeostatic sleep regulation in habitual short sleepers and long sleepers. Am J Physiol 1996;270:R41-R53.

23 Steriade M, Nuñez A, Amzica F: A novel slow $(<1 \mathrm{~Hz})$ oscillation of neocortical neurons in vivo: Depolarizing and hyperpolarizing components. J Neurosci 1993; 13:3252-3265.

24 Steriade M, Nuñez A, Amzica F: Intracellular analysis of relations between the slow $(<1 \mathrm{~Hz})$ neocortical oscillation and other sleep rhythms of the electroencephalogram. J Neurosci 1993; 13:3266-3283.

25 Steriade M, Contreras D, Curro Dossi R, Nuñez A: The slow $(<1 \mathrm{~Hz})$ oscillation in reticular thalamic and thalamocortical neurons: Scenario of sleep rhythm generation in interacting thalamic and neocortical networks. J Neurosci 1993;13:3284-3299.

26 Achermann P, Borbély AA: Low-frequency $(<1$ $\mathrm{Hz}$ ) oscillations in the human sleep EEG. Neuroscience 1997;81:213-222.

27 Tobler I, Borbély AA, Groos G: The effect of sleep deprivation on sleep in rats with suprachiasmatic lesions. Neurosci Lett 1983;42:49-54.

28 Mistlberger RE, Bergmann BM, Waldenar W, Rechtschaffen A: Recovery sleep following sleep deprivation in intact and suprachiasmatic nuclei lesioned rats. Sleep 1983;6:217-233.

29 Trachsel L, Edgar DM, Seidel WF, Heller WC, Dement WC: Sleep homeostasis in suprachiasmatic nuclei-lesioned rats: Effects of sleep deprivation and triazolam administration. Brain Res 1992;589:253-261.

30 Franken P, Tobler I, Borbély AA: Varying the photoperiod in the rat: Profound effect on the 24-hour sleep pattern but no effect on sleep homeostasis. Am J Physiol 1995;269:R691R701.

31 Dijk DJ, Daan S: Sleep EEG spectral analysis in a diurnal rodent: Eutamias sibiricus. J Comp Physiol A 1989;165:205-215.

32 Tobler I, Deboer T: Sleep, sleep regulation and cortical temperature in a photoperiodic rodent. J Sleep Res 1994;3:254.

33 Dijk DJ, Czeisler CA: Paradoxical timing of the circadian rhythm of sleep propensity serves to consolidate sleep and wakefulness in humans. Neurosci Lett 1994;166:63-68.

34 Czeisler CA, Duffy JF, Shanahan TL, Brown EN, Mitchell JF, Dijk DJ, Rimmer DW, Ronda JM, Allan JS, Emens JS, Kronauer RE: Reassessment of the intrinsic period of the human circadian pacemaker in young and older subjects. Sleep Res 1995;24A:505.

35 Borbély AA, Achermann P, Trachsel L, Tobler I: Sleep initiation and sleep intensity: Interaction of homeostatic and circadian mechanisms. J Biol Rhythms 1989;4:149-160.

36 Edgar DM, Dement WC, Fuller CA: Effect of SCN lesions on sleep in squirrel monkeys: Evidence for opponent processes in sleep-wake regulation. J Neurosci 1993; 13:1065-1079.

37 Achermann P, Borbély AA: Simulation of daytime vigilance by additive interaction of a homeostatic and a circadian process. Biol Cybern 1994;71:115-121.

38 Oleksenko AI, Mukhametov LM, Polyakova IG, Supin AY, Kovalzon VM: Unihemispheric sleep deprivation in bottlenose dolphins. J Sleep Res 1992;1:40-44.

39 Krueger JM, Obál F: A neuronal group theory of sleep function. J Sleep Res 1993;2:63-69.

40 Benington JH, Heller HC: Restoration of brain energy metabolism as the function of sleep. Prog Neurobiol 1995;45:347-360.

41 Benington JH, Kodali SK, Heller HC: Stimulation of $\mathrm{A}_{1}$ adenosine receptors mimics the electroencephalographic effects of sleep deprivation. Brain Res 1995;692:79.

42 Satoh S, Matsumura H, Suzuki F, Hayaishi O: Promotion of sleep mediated by the $\mathrm{A}_{2 \alpha}$-adenosine receptor and possible involvement of this receptor in the sleep induced by prostaglandin $\mathrm{D}_{2}$ in rats. Proc Natl Acad Sci USA 1996;93: 5980-5984.

43 Schwierin B, Borbély AA, Tobler I: Effects of $\mathrm{N}^{6}$-cyclopentyladenosine and caffeine on sleep regulation in the rat. Eur J Pharmacol 1996; 300:163-171.

44 Landolt HP, Dijk DJ, Gaus SE, Borbély AA: Caffein reduces low-frequency delta activity in the human sleep EEG. Neuropsychopharmacology 1995;12:229-238.

45 Landolt HP, Werth E, Borbély AA, Dijk DJ: Caffein intake $(200 \mathrm{mg})$ in the morning affects human sleep and EEG spectra at night. Brain Res 1995;675:67-74.

46 Kattler H, Dijk DJ, Borbély AA: Effect of unilateral somatosensory stimulation prior to sleep on the sleep EEG in humans. J Sleep Res 1994:3:159-164.

47 Werth E, Achermann P, Borbély AA: Brain topography of the human sleep EEG: Anteroposterior shifts of spectral power. Neuroreport 1996;8:123-127.

48 Werth E, Achermann P, Borbély AA: Frontooccipital EEG power gradients in human sleep. J Sleep Res 1997;6:102-112.

49 Horne JA: Human sleep, sleep loss and behavior: Implications for the prefrontal cortex and psychiatric disorder. Br J Psychiatry 193;162: 413-419. 